\title{
Cdc34 and the F-box protein Met30 are required for degradation of the Colk-inhibitory kinase Swel
}

\author{
Peter Kaiser, ${ }^{1}$ Rey A.L. Sia, ${ }^{2}$ Elaine G.S. Bardes, ${ }^{2}$ Daniel J. Lew, ${ }^{2}$ and Steven I. Reed ${ }^{1,3}$ \\ ${ }^{1}$ The Scripps Research Institute (TSRI), La Jolla, California 92037 USA; ${ }^{2}$ Department of Pharmacology and Cancer Biology, \\ Duke University M edical Center, Durham, N orth Carolina 27710 USA
}

\begin{abstract}
Ubiquitin-mediated proteolysis controls the abundance of many cell cycle regulatory proteins. Recent work in Saccharomyces cerevisiae suggests that a complex consisting of Cdc53, Skpl, and a third component known as an F-box protein (termed SCF) in combination with Cdc34 specifically targets regulatory proteins for degradation, and that substrate specificity is likely to be mediated by the F-box subunit. A screen for genetic interactions with a cdc34 mutation yielded MET 30, which encodes an F-box protein. MET 30 is an essential gene required for cell cycle progression and met30 mutations interact genetically with mutations in SCF components. Furthermore, physical interactions between Met30, Cdc53, Cdc34, and Skpl in vivo provide evidence for an SCF ${ }^{\mathrm{Met} 30}$ complex. We demonstrate the invol vement of Met30 in the degradation of the Cdk-inhibitory kinase Swel. Swel is stabilized in met30 mutants and GST-Met30 pull-down experiments reveal that Met30 specifically binds Swel in vivo. Furthermore, extracts prepared from cdc34 or met30 mutants are defective in polyubiquitination of Swel. Taken together, these data suggest that SCF-mediated proteolysis may contribute to the regulation of entry into mitosis. Our data, in combination with previously published results, also provide evidence for distinct SCF complexes in vivo and support the idea that their F-box subunits mediate SCF substrate specificity.
\end{abstract}

[Key Words: Met30; F-box; Swe1; SCF; ubiquitination]

Received March 6, 1998; revised version accepted July 2, 1998.

Proteolysis is one of the principal mechanisms whereby cellular protein levels are regulated. Therefore, it is not surprising, that cell cycle transitions are frequently controlled by degradation of regulatory proteins. Proteolysis is particularly suitable for cell cycle regulation, because it is a rapid irreversible process and, thus, ensures unidirectional progression through cell cycle phase transitions.

In eukaryotes, most regulated proteolysis is initiated by polyubiquitination of target proteins. Ubiquitination requires ATP-dependent activation of ubiquitin by ubiquitin-activating enzymes (E1), transfer to a conserved cystein resi due on ubiquitin-conjugating enzymes (E2 or $\mathrm{Ubc}$ ) and, finally, conjugation of ubiquitin to target proteins. Ubiquitin conjugation often requires specificity factors (E3 or ubi quitin ligase) that are thought to recognize and directly interact with substrate proteins, and, in some cases, serve as thiol-ubiquitin intermediates. The E1-E2-E3 reaction cascade results in polyubiquitination of substrate proteins on Iysine resi dues. These polyubiquitinated proteins are subsequently recognized and degraded by the $26 \mathrm{~S}$ proteasome, a complex protease-containing organelle (Hochstrasser 1996).

${ }^{3}$ Corresponding author.

E-MAIL sreed@scripps.edu; FAX (619) 784-2781.
Eukaryotes express a family of distinct E2 enzymes. All share characteristic motifs that have allowed the identification of the complete set of E2 enzymes in Saccharomyces cerevisiae (U bc1-U bc13) by sequence analysis of the S. cerevisiae genome. Although E2 enzymes confer some substrate specificity, the general view is that E3 enzymes are responsible for the majority of substrate recognition and targeting, and are therefore the components subjected to regulation. Despite their central role, E3 enzymes are the least well-characterized factors involved in ubiquitination, probably because they generally do not share a single identifying sequence motif or mode of action. However, several families of proteins with E3 function have been identified, including the HECT domain proteins (Huibregtse et al. 1995), Ubrl-related ubiquitin ligases (Varshavsky 1996), and the anaphase-promoting complex (APC, also called the cyclosome) (Lamb et al. 1994; Irniger et al. 1995; King et al. 1995; Sudakin et al. 1995).

Recent work in S. cerevisiae suggests that a complex consisting of Cdc53, Skpl, and Cdc4 functions as an E3 ubiquitin ligase for the Cdk-inhibitor Sicl (Bai et al. 1996; Feldmann et al. 1997; Skowyra et al. 1997). This complex has been termed SCFCdc4 (Skpl-Cullin (or Cdc53)-F-box protein) indicating that the F-box protein in this particular complex is C dc4. F-box proteins share 
a short sequence motif, the F-box, which has been shown to mediate binding to Skpl (Bai et al. 1996). Data base searches have revealed that $\mathrm{F}$-box proteins exist as a small family. Interestingly, the yeast F-box protein Grrl has been linked to $G_{1}$-cyclin proteolysis (Barral et al. 1995) and a physical interaction with the $G_{1}$ cyclins $\mathrm{CIn} 1$ and $\mathrm{CIn} 2$ has been demonstrated in vitro (Skowyra et al. 1997) suggesting the existence of an SCF ${ }^{\mathrm{Grr}}{ }^{\mathrm{c}}$ complex. These observations have led to the proposal of a model in which different F-box proteins associated with Skp1 and Cdc53 define the substrate specificity of SCF ubiquitin ligase complexes (Bai et al. 1996; Feldmann et al. 1997; Skowyra et al. 1997). SCF-dependent ubiquitin conjugation in budding yeast has been shown to be catalyzed by the E2 enzyme Cdc34, which interacts with Cdc53 and can ubiquitinate Sicl and CIn2 (Deshaies et al. 1995; M athias et al. 1996; Willems et al. 1996; Verma et al. 1997). Currently, however, it cannot be ruled out that other E2 enzymes function in conjunction with SCF.

In a genetic screen designed to identify limiting components of the Cdc34-dependent ubiquitination pathway, we isolated the gene encoding the F-box protein M et30. MET30 is an essential gene and has been recently implicated in repression of genes required for methionine metabolism. Mutants harboring the dominant MET30-1 allele were shown to fail to repress expression of MET25, a gene required for methionine biosynthesis, in response to S-adenosylmethionine (Thomas et al. 1995). However, this defect cannot explain the lethality confered by met30 loss-of-function mutations.

Here, we report that $M$ et30 is required for proteolysis of the Cdk-inhibitory kinase Swel. Swel is the S. cerevisiae homolog of fission yeast Weel and phosphorylates the cyclin-dependent kinase Cdc28 on tyrosine 19 (Booher et al. 1993). Phosphorylation of specific tyrosines by Weel-like kinases renders cyclin-dependent kinases inactive. Entry into mitosis in many organisms is largely regulated by Weel-dependent tyrosine phosphorylation followed by dephosphorylation of Cdks (Dunphy 1994). Although the enzymatic machinery that controls tyrosine phosphorylation and dephosphoryIation of C dks is conserved in budding yeast, phosphorylation on tyrosine 19 of $\mathrm{C} \mathrm{dc} 28$ is not required for proper timing of mitosis during the unperturbed cell cycle (Russell et al. 1989; A mon et al. 1992; Booher et al . 1993). However, it is critical for the inhibition of mitosis in response to activation of the morphogenesis checkpoint (Lew and Reed 1995a,b) and participates in adaptation from other checkpoint arrests (Rudner and Murray 1996).

In this paper we show that the F-box protein M et30 is part of an SCF ${ }^{\mathrm{M} \text { et30 }}$ complex in vivo and specifically targets Swel to the Cdc34-dependent proteolysis pathway. These results link regulation of tyrosine phosphorylation of Cdks with SCF-regulated proteolysis. Because highly conserved M et30 homologs are found in other eukaryotes, including mammals, SCF-mediated ubiquitination of Weel-like kinases may play a significant role in control of entry into mitosis.

\section{Results}

Isolation of MET30 as an enhancer of cdc34-3 mutants

The S. cerevisiae ubiquitin-conjugating enzyme Cdc34 has been implicated in the proteolysis of several key regulatory proteins, including the $\mathrm{Cdk}$ inhibitors Sicl and Far1 (McKinney et al. 1993; Feldmann et al. 1997; Skowyra et al. 1997), the $G_{1}$ cyclins CIn1, CIn2, CIn3 (Deshaies et al. 1995; Yaglom et al. 1995; Lanker et al. 1996), and the DN A replication factor Cdc6 (Piatti et al. 1996; Drury et al. 1997). The current model predicts that different E3 ligases mediate substrate specificity. To identify such E3 enzymes, we used a hapl oinsufficiency screen with a temperature-sensitive cdc34 mutant. We reasoned that a $50 \%$ reduction of a limiting component in the Cdc34 pathway should result in enhancement of the temperature sensitivity of diploid cdc34-3 cells (for description of the rationale of the screen, see Marini et al. 1996). Therefore, we mutagenized diploid cdc34-3 mutants by random heterozygous transposon-mediated gene disruptions (see Materials and Methods), and selected mutants that were unable to grow at the semipermissive temperature of the parental strain $\left(32^{\circ} \mathrm{C}\right)$. Three such mutants exhibited a 2:2 segregation of lethality linked to the inserted U RA 3 marker associated with the transposon. Sequence analysis of the DN A flanking the transposon insertion sites revealed that the same ORF was disrupted in all three mutants and that the site of integration for two mutants was identical. Analysis of the disruption sites by use of the Yeast Genome Data Base identified the mutated gene as MET30. To verify that mutation of MET30 caused the enhancement of the temperature sensitivity in the three mutants, we replaced one copy of the entire MET30 ORF in a diploid cdc34-3 mutant with a gene conferring resistance to the drug G418. This heterozygous gene disruption resulted in the same reduced permissive temperature for cdc34-3 mutants that we observed with the original enhancer mutants (Fig. 1A). A disruption of one copy of MET30 in a diploid wild-type strain did not affect growth at any temperature (data not shown). Tetrad analysis of the heterozygously disrupted wild-type strain revealed a 2:2 segregation of lethal ity with all viable spores being sensitive to $\mathrm{G} 418$, confirming that MET30 is an essential gene, as has been reported previously (Thomas et al. 1995).

\section{Met30 interacts genetically with Cdc53, Cdc34, and Skpl}

To analyze the functional relationship between $M$ et30 and proteins involved in the Cdc34-dependent ubiquitination pathway, we next tested for genetic interactions with other SCF components. To carry out a detailed genetic analysis, we constructed temperaturesensitive met30 mutants. For this purpose, the coding region of MET30 was mutagenized in vitro by PCR and mutants unable to grow at $37^{\circ} \mathrm{C}$ were selected. One of these, met30-6, was chosen for further analysis.

We had al ready demonstrated a genetic interaction be tween cdc34 temperature sensitivity and MET30 gene 
A

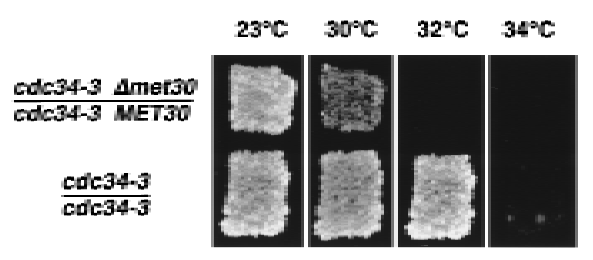

B
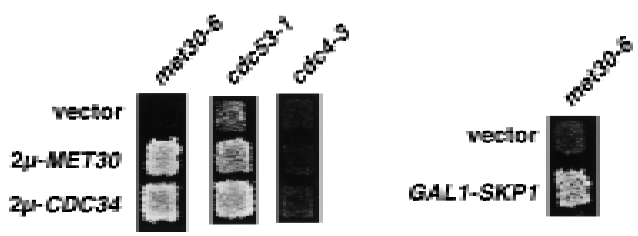

Figure 1. Genetic interactions between MET30, CDC34, and SCF components. (A) Herterozygous disruption of MET30 enhances the temperature sensitivity of diploid cdc34-3 mutants. Cells were grown at $23^{\circ} \mathrm{C}$, sequentially replica plated to four new plates, and incubated at the temperatures indicated. (B) High-copy suppression. met30-6, cdc53-1, and cdc4-3 mutants were transformed with $2 \mu$-based plasmids harboring no insert

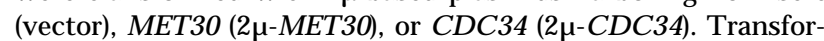
mants were grown at $23^{\circ} \mathrm{C}$ and replicas were incubated at $34^{\circ} \mathrm{C}$ (met30-6 and cdc53-1) or $30^{\circ} \mathrm{C}$ (cdc4-3). To analyze genetic interactions between MET 30 and SKP1, met30- 6 mutants expressing SKP1 under control of the GAL1 promoter were grown on glucose plates at $23^{\circ} \mathrm{C}$, replica plated to galactose plates to induce expression of SKP1 and incubated at the restrictive temperature of $34^{\circ} \mathrm{C}$.

dosage (Fig. 1A). To provide additional support for this interaction, we transformed haploid met30-6 mutants with CDC34 cloned into a high-copy plasmid. Increased dosage of C dc34 suppressed the lethal ity of met30-6 mutants at a normally nonpermissive temperature $\left(34^{\circ} \mathrm{C}\right)$. As expected, MET30 on a high-copy plasmid rescued the mutant as well (Fig. 1B). We then extended the same kind of analysis to cdc53-1 and cdc4-3 mutants. The growth defect of cdc53-1 mutants at restrictive temperature was suppressed by both high-copy MET30 and highcopy CDC34. However, increased levels of Met30 or Cdc34 did not rescue cdc4-3 mutants. Finally, a genetic link between SKP1 and MET 30 was established, because overexpression of Skpl suppressed the temperature sensitivity of met30-6 mutants (Fig. 1B).

Met30 physically interacts with Cdc34, Cdc53, and Skpl

These genetic data suggest that C dc34, Cdc53, and Skp1 interact with $\mathrm{M}$ et30. However, genetic interactions can result from indirect physiological interactions. Therefore, we sought direct evidence for a physical association between $\mathrm{M}$ et30 and components of the $\mathrm{Cdc} 34$-dependent ubiquitination machinery. Proteins from cells expressing biologically active GST-tagged Skpl and epitope- tagged M et30(HA)3 were purified on glutathione beads. Proteins bound to the beads were eluted with glutathione and anal yzed by immunobl otting. M et30 specifically copurified with Skp1 (Fig. 2A). We then performed coimmunoprecipitation experiments with strains expressing $M$ et30 tagged with the RGS6H epitope and C dc34(HA)3 or $\mathrm{Cdc53}(\mathrm{HA}) 3$, respectively. Met30 was found in immune complexes with Cdc34 and Cdc53 (Fig. 2B). The two mobility species of $\mathrm{Cdc} 53$ detected are consistent with a report suggesting that the slower migrating isoform of Cdc53 is modified with the ubiquitin-related protein Rub1 (Lammer et al. 1998). Whereas the stoichiometry of the M et30/C dc53 association was unchanged in different experiments, the amount of Met30 associated with $\mathrm{Cdc} 34$ was very variable but always significant.

Taken together, both the genetic and the biochemical results suggest that $\mathrm{M}$ et30 is part of a multiprotein com-

A

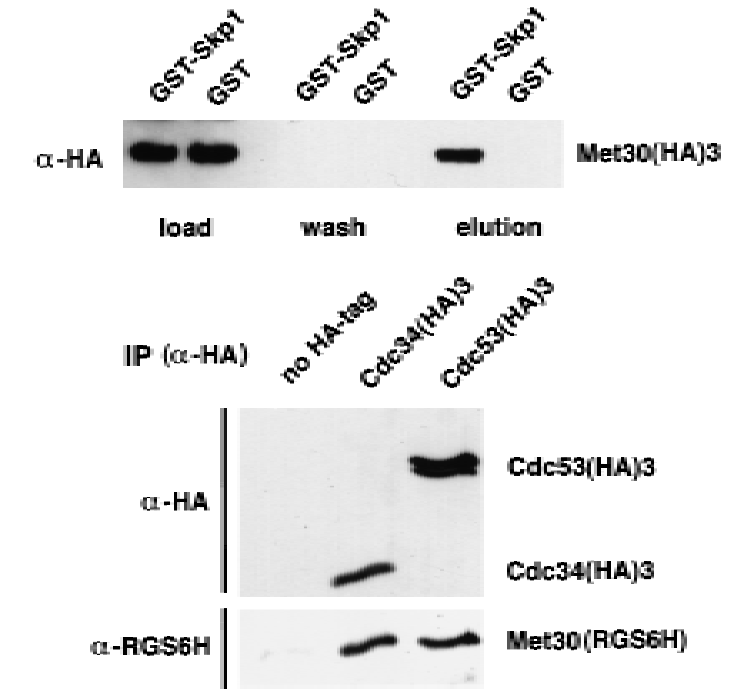

Figure 2. Physical interaction of M et 30 with $\mathrm{Skp1}, \mathrm{Cdc} 34$, and Cdc53. (A) Met30 forms a complex with Skpl in vivo. Cells harboring an endogenously expressed (HA)3-tagged MET30 and expressing GST-SKP1 or GST under the control of the CUP1 promotor were grown in the presence of $100 \mu \mathrm{M}$ copper to an $\mathrm{OD}_{600} \cong 0.5$. Protein extracts were incubated with glutathione beads. After several washes with binding buffer the beads were washed with binding buffer, including $0.8 \mathrm{M}$ of sodium chloride (wash). Bound proteins were eluted with glutathione and subjected to Western blot analysis with an antibody directed against the HA epitope. Probing the blot with antibodies directed against GST reveal ed a two- to threefold excess of GST compared with GST-Skp1 (data not shown). (B) M et30 is in a complex with Cdc34 and $\mathrm{Cdc} 53$ in vivo. Cells expressing a RGS6H epitope-tagged MET30 under control of the GAL1 promotor and harboring either endogenously expressed (HA)3tagged CDC34 or CDC53 were grown in galactose to an $O D_{600} \cong 0.5$. Immunocomplexes were purified with $12 C A 5$ antibodies (directed against the HA epitope) coupled to protein A, separated by SDS-PAGE, and analyzed by immunoblotting with antibodies directed against the HA or the RGS6H epitopes to detect Cdc53 and Cdc34 or M et30, respectively. Cells expressing $\mathrm{M}$ et30(RGS6H) but no HA-tagged protein were used as a control (no HA tag). 
plex with Cdc34, Cdc53, and Skp1. In accordance with the previously proposed nomenclature, we refer to the

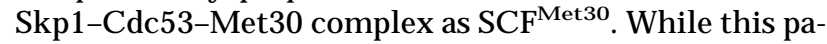
per was being revised, a similar analysis that arrived at the same conclusion was published (Patton et al. 1998).

\section{Swel is a potential target of SCF ${ }^{\text {Met30 }}$}

The arrest phenotype of met30-6 mutants at $37^{\circ} \mathrm{C}$ was heterogeneous, including both budded and unbudded cells with either $G_{1}$ or $G_{2} / M$ DNA content. The majority of the population arrested as round unbudded cells. We noticed that a fraction of the budded met30-6 cells displayed an elongated bud phenotype (Fig. 3C), which is characteristic of cells in which activation of Clbl-4/ Cdc28 kinase has been delayed or prevented (Lew and Reed 1993). One mechanism whereby CIb1-4/C dc28 activation can be blocked is inhibitory phosphorylation of Cdc28 at tyrosine 19 by the kinase Swel (Booher et al. 1993). This phosphorylation is reversed by the phospha-
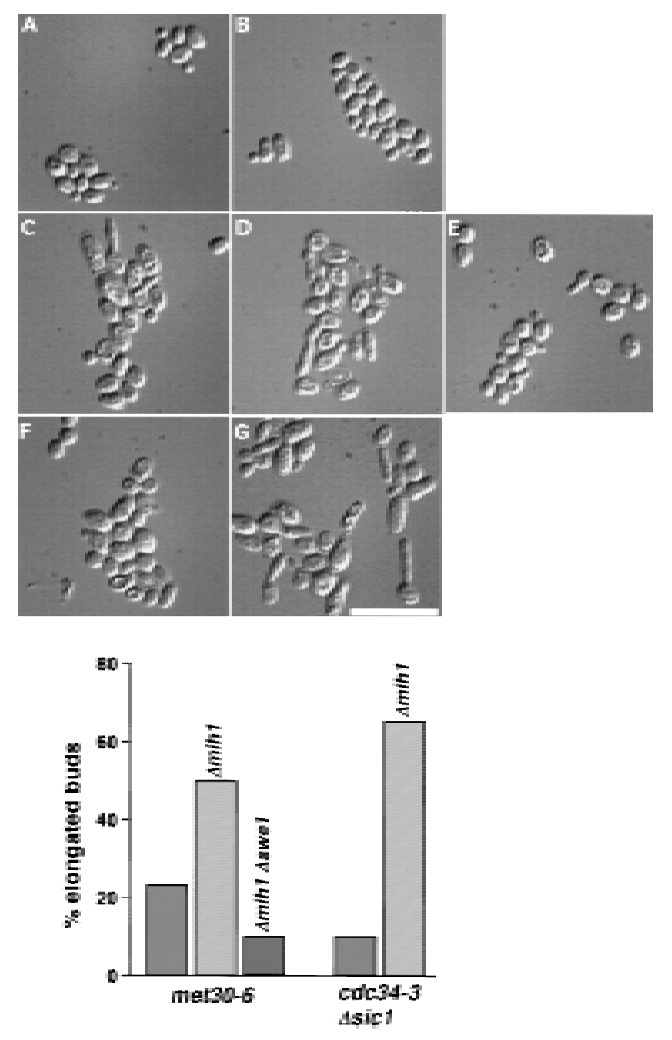

Figure 3. Hyperactivation of the Swel pathway in met30 and cdc34 mutants. Cells were grown at $23^{\circ} \mathrm{C}$ in YEPD and shifted to $37^{\circ} \mathrm{C}$ for $5 \mathrm{hr}$, followed by fixation in $70 \%$ ethanol and visualization by DIC microscopy. Strains were as foll ows (percent of el ongated cells or buds in the population are indicated in parentheses): (A) wild type (0\%), (B) mih1::LEU $2(0 \%)$, (C) met30-6 (23\%), (D) met30-6 mih1::LEU 2 (50\%), (E) met30-6 mih1::LEU 2 swel::U RA3 (10\% - these were smaller and less straight than the elongated buds in $C$ and D), (F) cdc34-3 sicl::U RA3 (10\%), (G) cdc34-3 sic1::U RA 3 mih1::LEU 2 (65\%). Two hundred cells were counted in each sample. Bar, $10 \mu \mathrm{m}$. The graph illustrates the percentage of cells with elongated buds. tase Mih1 leading to the activation of the C dc28 kinase (Russell et al. 1989). To determine whether this regulatory pathway might be affected in met30 mutants, we generated met30-6 mih1::LEU 2 and met30-6 mih1::LEU 2 swel::U RA3 strains. At $37^{\circ} \mathrm{C}$, the met30-6 mih1::LEU 2 cells arrested with a much higher proportion of cells exhibiting the el ongated bud phenotype (Fig. 3D), whereas el ongated buds were almost absent in the met30-6 mih1::LEU 2 swel::U RA 3 cells (Fig. 3E). As described previously, deletion of $\mathrm{MIHI}$ in an otherwise wild-type strain did not cause a significant cell cycle delay or lead to generation of cells with el ongated buds (Fig. 3A,B). This result suggested that Swel might be more abundant or more active in met30-6 cells than in wild-type cells.

A role for $\mathrm{Cdc3} 4$ in control of the Swel/Mihl pathway has not been reported, but such a role might have been missed because the failure of cdc34 mutants to degrade the Cdk inhibitor Sicl leads to a cell cyclearrest prior to $\mathrm{G}_{2}$, when Swel and Mihl become relevant to cell cycle progression. cdc34-3 sicl::U RA3 cells arrested in $\mathrm{G}_{2} / \mathrm{M}$ with a predominantly large round bud phenotype (Fig. 3F), as reported previously (Schwob et al. 1994). To determine whether an increase in Swel activity occurred in cdc34-3 mutants, we generated a cdc34-3 si c1::U RA3 mih1::LEU 2 strain. At $37^{\circ} \mathrm{C}$, a large proportion (65\%) of these cells arrested with el ongated buds (Fig. 3G). Deletion of SWE1 in cdc34-3sic1::U RA mutants did not supress the $\mathrm{G}_{2} / \mathrm{M}$ arrest phenotype, suggesting that accumulation of another Cdc34 target is responsible for this cell cycle arrest (data not shown). However, these cells no longer had elongated buds (data not shown), indicating that this component of the phenotype is caused by Swel.

In combination, these findings suggest that one defect in both met30 and cdc34 mutants is a higher level of Swel protein or activity. This does not make a major contribution to the arrest phenotype of either mutant al one because $\mathrm{M}$ ih1 suffices to keep $\mathrm{Cdc} 28$ sufficiently active; deletion of $\mathrm{MIHI}$ uncovers a role for these proteins in controlling $\mathrm{Cdc} 28$ tyrosine phosphorylation.

Given the expectation that Met30 and Cdc34 act by targeting proteins for ubiquitination and subsequent degradation, the simplest explanation of the above findings would be that Swel is itself a target of SCFMet30. Consistent with this explanation, analysis of the Swel sequence revealed two regions with PEST motifs characteristic of unstable proteins (Rogers et al. 1986) that are often targets of the Cdc34-dependent ubiquitination pathway. To examine the stability of Swel protein, a 12 myc epitope tag was fused to the carboxyl terminus of Swel, and expression of this construct was placed under the control of the inducible GAL1 promoter. Wild-type and met30-6 mutant cells contai ning this construct were incubated at $37^{\circ} \mathrm{C}$ for $2 \mathrm{hr}$, induced to express Swelmyc12 with galactose for $10 \mathrm{~min}$, and then labeled with $\left[{ }^{35}\right.$ S]methionine/cysteine for $10 \mathrm{~min}$. Swel-myc12 expression was subsequently turned off by transferring the cells to dextrose medium, and an excess of cold methionine and casamino acids was added. Degradation of Ia- 
beled Swel-myc12 was significantly inhibited in the met30-6 mutant relative to wild type (Fig. 4A,C). In contrast, Swel-myc12 degradation in cdc4-3 mutants proceeded at wild-type rates (Fig. 4A,C). To exclude possi ble cell cycle position effects, we analyzed Swel turnover in cells synchronized in $\mathrm{S}$ phase. Cells were arrested by addition of hydroxyurea and pulse-chase analysis was performed as described above. Again, Swel-myc12 degradation was significantly inhibited in met30-6 mutants relative to wild type (Fig. 4B,C). The $\mathrm{G}_{1}$ cyclin, CIn2, was not stabilized in a met30-6 mutant, confirming that Swel stabilization is not caused by a general proteolysis defect associated with the met30-6 mutation (data not shown).

\section{Met30 physically interacts with Swel in vivo}

In the current model for SCF-mediated ubiquitination, F-box proteins specifically recognize and bind target proteins. A physical interaction between $\mathrm{Cdc} 4$ and its target Sicl, as well as binding of Grr1 to $C \ln 1$, has been demonstrated in vitro (Feldmann et al. 1997; Skowyra et al. 1997). We asked whether a complex of Met30 and its putative target Swel could be detected in vivo. Extracts were prepared from yeast cells expressing an epitopetagged allele of Swel and a GST-Met30 fusion, and Met30-associated complexes were purified on glutathione beads. Swel specifically copurified with GSTM et30, whereas no binding to GST was detected (Fig. 5).
This physical interaction is most likely required to target Swel to the Cdc34-degradation pathway.

In the experiment described above, Swel was expressed under the control of the GAL1 promoter that leads to cell cycle arrest as a result of inhibition of Cdc28 kinase activity. However, simultaneous overexpression of the B-type cyclin CIb2 suppresses this cell cycle arrest, presumably because excess $\mathrm{Clb} 2$ hyperactivated the Cdc28 kinase. Interestingly, overexpression of Clb2 increased the amount of Swel that copurified with M et30 (data not shown), suggesting a potential link between Clb2/Cdc28 mediated phosphorylation of Swel and $\mathrm{SCF}^{\mathrm{M} \text { et30 }}$ mediated ubiquitination.

Extracts prepared from cdc34 or met30 mutants are defective in Swel polyubiquitination

Our data suggest that Met30 is required for Swel ubiquitination. However, to establish a more direct link between M et30 function and Swel ubiquitination, we analyzed the ability of wild-type and mutant yeast cell extracts to ubiquitinate Swel. To this end, we incubated radiolabeled Swel, produced by in vitro translation, with whol e yeast cell extracts and anal yzed the reaction products by SDS-PAGE. Incubation with extracts prepared from wild-type cells resulted in accumulation of more slowly migrating forms of Swel (Fig. 6A). This reaction was dependent on the addition of ATP (data not shown). To ask whether the slower migrating forms of Swel were
A
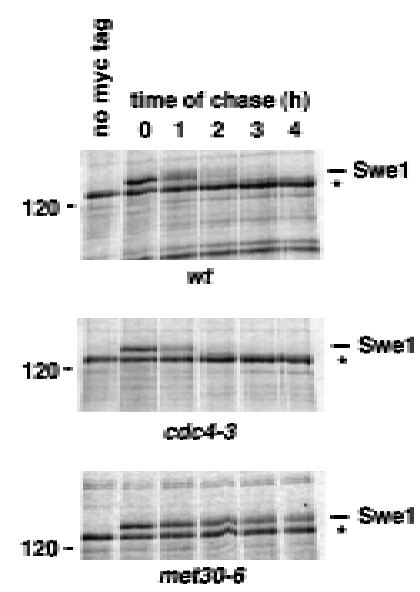

B

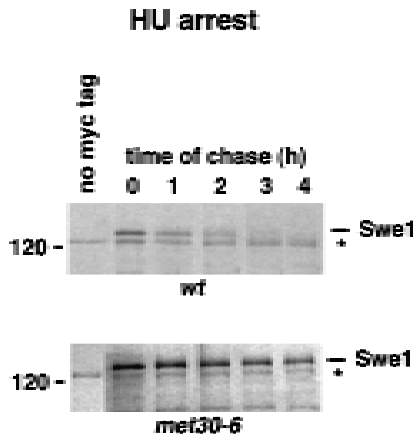

C

Figure 4. Swel is stabilized in met30 but not cdc4 mutants. (A) Wild-type (top), cdc4-3 (middle), or met30-6 (bottom) cells containing the GAL1-SWE1-myc12 construct were shifted to $37^{\circ} \mathrm{C}$ for $2 \mathrm{hr}$. Galactose was then added to $2 \%$ and the cells were incubated for a further $10 \mathrm{~min}$ to induce Swel-myc12 expression. Cells were then label ed $10 \mathrm{~min}$ at $37^{\circ} \mathrm{C}$ followed by termination of Swel synthesis and labeling during a 4-hr time course. The immunoprecipitated Swel was analyzed by SDS-PAGE and Phosphorlmaging. (Left lane) Immunoprecipitates from cells lacking the Swel-myc construct. The band running below Swel-myc12 (asterisk) is a background band. (B) A similar experiment was conducted with synchronized cells. Wild-type and met30-6 cells were arrested by addition of 200 $\mathrm{mm}$ hydroxyurea (HU) for $3 \mathrm{hr}$ at $23^{\circ} \mathrm{C}$ prior to the temperature shift to $37^{\circ} \mathrm{C}$. Cell cycle arrest was monitored visually $(>80 \%$ large budded cells). Pulse-chase analysis was performed as described in A but in the continuous presence of $200 \mathrm{~mm} \mathrm{HU}$. (C) The ${ }^{35} \mathrm{~S}-\mathrm{label}$ ed Swel-myc12 signal was quantitated by Phosphorlmager and ImageQuant v1.2 software, normalized to the background band and expressed as percent of signal at $\mathrm{t}=0$. 


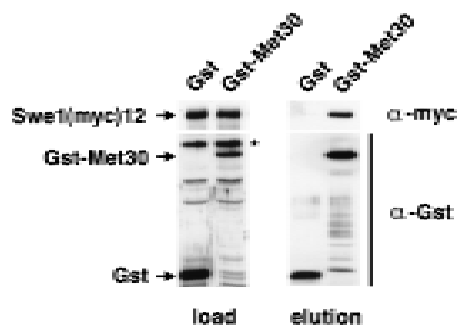

Figure 5. Met30 interacts physically with Swel. Cells were grown in YEP raffinose to an $\mathrm{OD}_{600} \cong 0.3$ and expression of Swel(myc)12, Clb2 and GST -M et30 was induced by addition of galactose for $3 \mathrm{hr}$. As a control, a strain expressing GST instead of GST-M et30 was processed in parallel. Protein complexes were purified on glutathione beads and parallel samples were separated on two SDS-polyacrylamide gels. After immunoblotting, one of the blots was probed with a polyclonal antibody directed against GST to detect GST-M et30 and GST, respectively. The other blot was analyzed with the $9 \mathrm{E} 10$ antibody against the myc epitope on Swel. (Asterisk) A protein crossreacting with the anti-GST antibody.

a result of polyubiquitination, we added mutant ubiquitin (U bi-R48) to the reaction. Mutation of Iysine 48 to arginine impairs chain elongation in polyubiquitination reactions because lysine 48 is the major site of isopeptide linkage between ubiquitin molecules (Chau et al. 1989). Addition of Ubi-R48 to the in vitro assay significantly reduced the mobility shift of Swel in response to incubation with wild-type extract, indicating that the more slowly migrating Swel forms correspond to polyubiquitinated species (Fig. 6A). To address the question of a requirement of Cdc34 and Met30 function for Swe1 polyubiquitination, we prepared extracts from cdc34 and met30 mutants. Whereas incubation of Swel with wildtype cell extracts resulted in the accumulation of polyubiquitinated species of Swel, no change in Swel mobility was observed after incubation with either mutant extract (Fig. 6B). This deficiency to catalyze Swel polyubiquitination is a result of impaired C dc 34 and $M$ et30 activity, respectively, rather than the result of a general inactivity of the extracts, because Swel ubiquitination is restored when both mutant extracts are combined. Cdc34 and Met30 functions are therefore required for polyubiquitination of Swel in vitro.

\section{Discussion}

The F-box components of SCF target distinct substrates to the $\mathrm{Cdc} 34$-dependent ubiquitination pathway

We isolated MET30 in a genetic screen on the basis of its strong specific interaction with a temperature-sensitive cdc34 mutation. The presence of an F-box motif in $M$ et30 immediately suggested that $M$ et30 might be part of an E3 complex targeting selected proteins to the Cdc34-dependent ubiquitination pathway. In this paper, we demonstrate the existence of such an E3 complex in vivo by showing that Met 30 physically associates with Skp1 and Cdc53 and refer to this complex as SCF ${ }^{\text {Met30. }}$
While this paper was being revised, similar results were reported by Patton et al. (1998). Whereas the F-box motif in M et30 suggests a direct interaction with Skp1 on the basis of previous work, we have no evidence for a direct physical contact between M et30 and Cdc53 or Cdc34. By use of insect cells expressing various combinations of Cdc4, Cdc53, Skp1, and Cdc34, a direct contact between Cdc4/Skpl, Skpl/Cdc53, and Cdc53/Cdc34, respectively, was proposed (Skowyra et al. 1997). We envision a similar situation, with $\mathrm{M}$ et30 replacing $\mathrm{Cdc} 4$ as the $\mathrm{F}$ box protein in this complex. This model suggests a rather nonspecific role for Skp1, Cdc53, and Cdc34 in SCF-mediated proteolysis, with C dc53 and Skpl serving principally as a bridge between F-box proteins and the ubiquitin-conjugating enzyme Cdc34. The F-box proteins may represent the specificity factors that physically interact with substrate proteins and enable their ubiquitination by $\mathrm{Cdc} 34$. On the basis of current data, the precise molecular organization of SCF complexes in vivo is not clear. For example, it has not yet been established whether individual SCF complexes consist of one molecule each of Cdc53, Skpl, and one F-box protein, or whether complexes of higher stoichiometry exist.

Little is known about the regulation of SCF activity. Two-hybrid experiments with the F-box protein Grrl have shown that the Grrl/Skpl interaction is modulated by carbon source ( $\mathrm{Li}$ and Johnston 1997), suggesting that complex formation between Skpl and the F-box component might be subjected to regulation, consequently influencing the rate of substrate proteolysis.
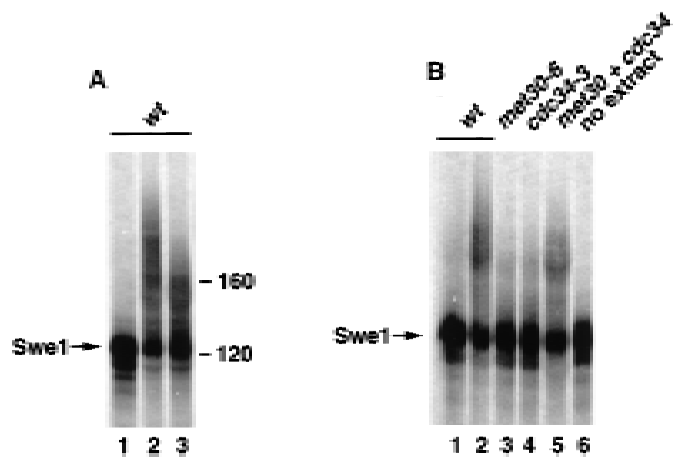

Figure 6. Swel in vitro ubiquitination. (A) Swel is ubiquitinated in whole cell extracts. ${ }^{35} \mathrm{~S}$-labeled Swel was incubated with whole yeast cell extracts at $23^{\circ} \mathrm{C}$ (lanes 2,3 ) or on ice (lane 1 ) in the presence of an ATP-regenerating system and ubiquitin (lanes 1,2) or mutant R48-ubiquitin (lane 3), respectively. The reaction mix was separated by SDS-PAGE and analyzed with a Phosphorlmager. (B) Swel ubiquitination is defective in cdc34 and met30 mutants. In vitro ubiquitination activity of extracts prepared from cdc34-3 or met30-6 mutants was compared with wild-type extracts. (Lane 5) Complementation experiment in which both mutant extracts were mixed (ratio, 2:1 =cdc343:met30-6). Extracts were preincubated at $23^{\circ} \mathrm{C}$ for $5 \mathrm{~min}$ to allow complex formation. ${ }^{35} \mathrm{~S}$-label ed Swel, ATP-regenerating system and ubiquitin were then added and reactions incubated at $23^{\circ} \mathrm{C}$ (lanes 2- 6) or on ice (lane 1 ). No extract was added to the reaction shown in lane 6 . Reaction products were analyzed as described in A. 
On the basis of the current model of SCF-mediated ubiquitination, it cannot be ruled out that ubiquitin conjugation to some substrates can be catalyzed by E2 enzymes other than $\mathrm{Cdc} 34$. It has been shown that glucoseinduced HXT1 expression depends on functional Cdc53 and Skp1, but not on Cdc34 (Li and Johnston 1997).

\section{Targets of M et30}

MET30 was originally identified in a screen for mutants defective in transcriptional repression of MET25 (Thomas et al. 1995). This screen resulted in the isolation of a dominant al lele, MET30-1, that was shown to impair adenosylmethionine-mediated transcriptional regulation. Furthermore, a two-hybrid interaction could be demonstrated between $\mathrm{M}$ et30 and the transcriptional activator of MET25, M et4 (Thomas et al. 1995). These results, together with our experiments that link Met30 with ubiquitin-dependent proteolysis, suggest M et4 as a possible target of $\mathrm{M}$ et30-mediated degradation. The constitutive transcription of MET25 observed may result from the hyperaccumulation of $\mathrm{M}$ et4 linked to a defect in M et30dependent proteolysis. However, Met4 stabilization in met30 mutants remains to be shown.

Recent work on the Hedgehog and Wingless signaling pathway in Drosophila suggests that the F-box protein $\mathrm{Slimb}$ is required for the degradation of $\beta$-catenin and other proteins. It has been proposed that Slimb is a homolog of S. cerevisiae Cdc4 (Jiang and Struhl 1998), but sequence comparison revealed that $\mathrm{M}$ et30 is, in fact, the closest budding yeast rel ative of Slimb (Fig. 7). Although budding yeast does not have a close homolog of $\beta$ catenin, it is conceivable that M et30 and Slimb target other proteins that have been conserved through evolution in both metazoa and yeast. It remains to be determined, for example, whether the metazoan homol ogs of Swel are targeted by an SCF complex containing Slimb (see below).

We report here that Swel is stabilized in met30 mutants, suggesting that the $\mathrm{Cdc} 28$-inhibitory kinase is degraded in a M et30-dependent manner. However, MET30 is an essential gene, with both del etion mutants and several different temperature-sensitive mutants arresting predominantly in $\mathrm{G}_{1}$ as unbudded cells. Defects in repression of genes involved in methionine bi osynthesis or failure to degrade Swel cannot explain this cell cycle arrest phenotype, suggesting that other proteins are subjected to Cdc34-dependent ubiquitination by M et30.

All of the budding yeast F-box proteins analyzed ge netically to date appear to be involved in the proteolysis of at least several proteins. Remarkably, they seem to target simultaneously both proteins implicated in cell cycle regulation and control of general metabolism. For example, Cdc4 has been implicated in ubiquitination of the cell cycle regulatory proteins Sic1, Far1, and Cdc6 (M cKinney et al. 1993; Drury et al . 1997; Fel dmann et al. 1997; Henchoz et al. 1997; Skowyra et al. 1997) as well as the transcriptional activator Gcn4 (D. Kor-

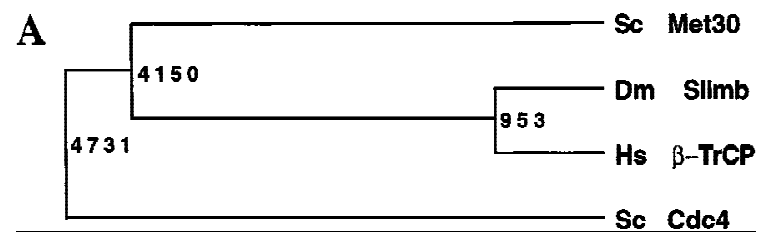

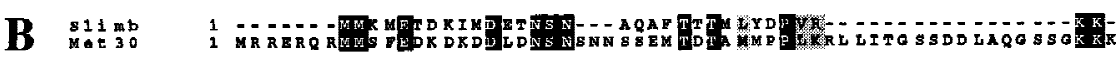

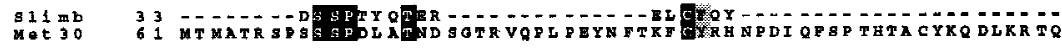

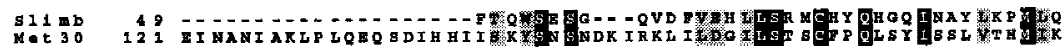 $811 m b$
M S11mb
MOt 30
23

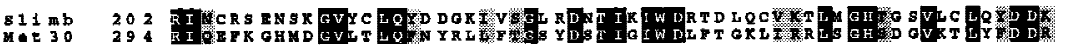

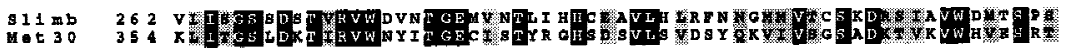

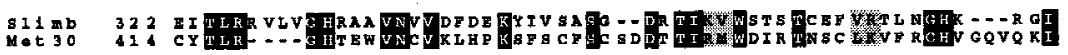

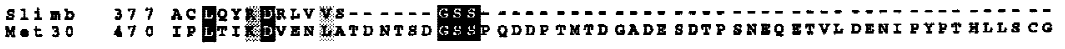

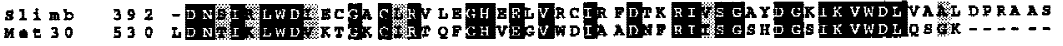 $811 \mathrm{mb}$
451

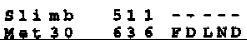

Figure 7. M et30 is closely related to Drosophila Slimb. (A) Dendrogram illustrating that Met30 is more closely related to Slimb and a human homolog h- $\beta$ TrCP (Margottin et al. 1998) than Cdc4. The dendrogram was generated with GeneWorks 2.5 software. (B) Met30 and Slimb sequences were aligned with Clustalw. Identical amino acids are shown as white letters on black background, and related residues as black letters on gray background. 
nitzer, pers. comm.). Similarly, Grrl is required for proteolysis of the $\mathrm{G}_{1}$ cyclins CIn1 and CIn2 (Barral et al. 1995) as well as a yet unknown target that mediates glucose repression. Thus, recognition and targeting by a particular F-box protein appears to depend more on protein structure than on function. Surprisingly though, there are no obvious sequence homologies relating substrates of a particular F-box protein. Thus, the mechanism whereby substrate specificity is achieved remains to be determined.

\section{SCF-mediated proteolysis and entry into mitosis}

In most eukaryotes, entry into mitosis is controlled by phosphorylation and dephosphorylation of cyclin-dependent kinases. Weel-like kinases phosphorylate Cdks on conserved tyrosine residues, thus inhibiting their activity. Dephosphorylation by $\mathrm{Cdc} 25$ phosphatases results in activation of the $\mathrm{Cdk}$ / cyclin complexes and triggers entry into mitosis. Our results demonstrate that Swel, the budding yeast homol og of Weel, is degraded in a M et30dependent manner. Weel might be regulated by $M$ et30 homologs in other eukaryotes, because proteins highly homologous to $M$ et30 are found in many other eukaryotes, including mammals. Furthermore, analyzing Weel protein sequences from various organisms (human, Xenopus, Drosophila, and fission yeast), we identified at least one PEST motif in each protein, suggesting that they are degraded by the Cdc34-SCF pathway. In fact, synchrony experiments in Schizosaccharomyces pombe have shown that Weel protein levels are greatly reduced at the onset of mitoses despite constant transcript levels (Aligue et al. 1997).

The abruptness of the $\mathrm{G}_{2} / \mathrm{M}$ transition is thought to be the result of positive feedback loops, with cyclin B/C dk activation leading to Weel inactivation and Cdc25 activation. It is possible that cyclin B/Cdk-mediated phosphorylation of Weel creates a signal for ubiquitination and leads to Weel degradation. Thus, SCF-mediated proteolysis may play a significant role in the regulation of the phosphorylation state of cyclin-dependent kinases, contributing to control of entry into mitosis.

In budding yeast, the presence of Swel does not affect cell cycle progression in the unperturbed cell cycle. However, when cell polarity is impaired, Swel introduces a prolonged $G_{2}$ delay, which has been ascribed to a checkpoint monitoring cell morphogenesis (Lew and Reed 1995a,b; Sia et al. 1996). Our findings suggest that Met30-dependent ubiquitination contributes to maintaining low Swel levels in unperturbed cells, and it will be interesting to determine whether this pathway may be blocked in response to the morphogenesis checkpoint.

\section{Materials and methods}

Yeast strains and culture

All yeast strains were isogenic to $15 \mathrm{Daub} \Delta$, a bar $1 \Delta$ ura3 $\Delta$ ns derivative of BF264-15D (MATa adel his2 leu2-3,112 trp1-1 ${ }^{\mathrm{a}}$ ) (Reed et al. 1985). All strains were grown in standard culture medium and standard yeast genetic methods were used (Guthrie and Fink 1991).

\section{Enhancer screen and cloning of MET 30}

A diploid cdc34-3 strain was transformed with three different pools of a mTn-3xHA/lacZ transposon mutagenized yeast genomic library resulting in random heterozygous gene disruptions marked with the U RA 3 gene (Burns et al. 1994, Ross et al . 1997). A total of 8000 uracil prototrophic transformants were replica plated to YEPD plates and incubated at semipermissive temperature $\left(32^{\circ} \mathrm{C}\right)$. Colonies that failed to grow at $32^{\circ} \mathrm{C}$ were picked from the master plate, retested, and sporulated. The disrupted genes from mutants that showed cosegregation of lethality and uracil prototrophy were identified by rescue of the $\mathrm{mTn}$ 3xHA/lacZ insertion including flanking regions (see http://ycmi.med.yale.edu/YGAC/home.html). The MET30 ORF including 1000 bp up- and downstream was amplified by PCR (primer PK55, 5'-GTCTGGTATACCGACACAG-3', and PK56, 5'-CCTCGGATTCAT ACTGGAA-3') and a 3.2-kb Xbal-Sphl fragment was subcloned into puc19 (resulting in plasmid Pp70) and YCplac33 (resulting in plasmid Pp88; Gietz and Sugino 1988). To disrupt MET30, a Hincll-Bglll fragment containing the entire coding region was replaced by a DN A fragment conferring kanamycin and $\mathrm{G} 418$ resistance [Hincll-H pal fragment from plasmid kanM X2 (Wach et al. 1994)].

\section{Construction of temperature-sensitive met30 mutants}

Temperature-sensitive met30 alleles were isolated following a procedure similar to the one described by Muhl rad et al. (1992). Briefly, primers PK55 and PK56 were used to amplify MET30 under mutagenic conditions ( $1 \mathrm{mM}$ dCTP, dTTP, $0.2 \mathrm{mM}$ dGTP, dATP, 30 pmole of each primer, $7 \mathrm{~mm} \mathrm{M} \mathrm{gCl}, 0.5 \mathrm{~mm} \mathrm{MnCl}, 20$ $\mathrm{mM}$ Tris- $\mathrm{HCl}$ at $\mathrm{pH} 8.4,50 \mathrm{~mm} \mathrm{KCl}$, and 0.5 units of Taq DNA polymerase in a total volume of $100 \mu \mathrm{l}$ ). The PCR product was cotransformed with Pstl-cut Pp88 into a strain disrupted for MET 30 and kept alive by a GAL1-MET30 inducible allele. The Pstl digestion removes most of the MET30 coding region and the gap was repai red in vivo by homologous recombination with the mutagenized MET30 PCR fragment. Transformants were grown on glucose plates at $25^{\circ} \mathrm{C}$, replica plated and colonies unable to grow at $37^{\circ} \mathrm{C}$ were selected. Plasmids containing temperaturesensitive met 30 allel es were rescued, a Xbal-Sphl fragment containing the gene was subcloned into YIplac204 (Gietz and Sugino 1988), and the met30 mutant alleles were then integrated at the TRP1 locus.

\section{Immunoprecipitations}

Strains expressing carboxy-terminal epitope-tagged proteins were constructed by inserting the DN A sequence encoding the epitope tag in front of the stop codon. All tagged proteins were functional because they rescued a strain deleted for the corresponding gene. Amino-terminal GST-tagged Skpl was expressed under the control of the CUP1 promoter on a single copy plasmid. An Xbal-Kpnl fragment (from plasmid pYEX ${ }^{T M} 4 T$, Amrad Biotech) containing the CUP1 promotor in front of the GST-coding region was ligated with Xbal-Kpnldigested Y C plac33 (resulting in plasmid Pp87; Gietz and Sugino 1988). The Skpl coding region was amplified with PCR primers that added a BamHI site to each end and cloned into the single BamHI site of Pp87. Expression of GST-Skpl was induced by addition of $\mathrm{CuSO}_{4}$ to a final concentration of $100 \mu \mathrm{m}$. For immunoprecipitations cells were broken with glass beads in buffer A $(50 \mathrm{~mm}$ Tris- $\mathrm{HCl}$ at $\mathrm{pH} 7.5,150 \mathrm{~mm} \mathrm{~N} \mathrm{aCl}, 0.1 \% \mathrm{~N} \mathrm{P} 40,10 \mathrm{~mm}$ sodium pyrophosphate, $5 \mathrm{~mm}$ EDTA, $5 \mathrm{~mm}$ EGTA, $0.1 \mathrm{~mm}$ orthovanadate, $1 \mathrm{~mm}$ PMSF, and $2 \mu \mathrm{g} / \mathrm{ml}$ aprotinin, leupeptin, and 
pepstatin) by $5 \times 1$ min vortexing with 1 -min cooling intervals on ice. Cell debris was sedimented for $15 \mathrm{~min}$ at $14000 \mathrm{~g}$ and protein concentration was determined by absorption at $280 \mathrm{~nm}$. A total of $500 \mu \mathrm{g}$ of protein was incubated with 12 CA 5 antibodies (ascites fluid) directed against the HA epitope (covalently coupled to protein A beads) or glutathione beads, respectively. Unbound proteins were removed by four washes in $1 \mathrm{ml}$ of buffer $A$, and bound proteins were eluted by boiling in $100 \mu$ of gel-loading buffer. Proteins were separated by SDS-PAGE and analyzed by immunoblotting with anti-HA (12CA5, BAbCO) anti-RGS6H (Qiagen), or anti-GST antibodies (prepared by immunizing rabbits with purified GST purified from Escherichia coli), respectively.

\section{Construction of the GAL-SWE1-myc12 plasmid}

A 3.7-kb Xbal-BamHI fragment from pSWE1-HA (Booher et al .1993) containing GAL1-SWE1-HA was cloned into an altered version of pRS306 that had the polylinker sites from Kpnl to Smal deleted. The Nhel site in the HA tag sequence was converted into a Sall site, the DNA was digested with Nhel and ligated with a 100-fold molar excess of the synthetic oligonucleotide 5'-CTAGCGTCGACG-3', which anneals to itself to generate a Sall site that ligates into the Nhel site. A 400-bp Xhol-Sall fragment containing 12 tandem copies of the myc epitope (P. Russell, TSRI) was cloned into the generated Sall site. The construct was digested with Stul for integration at URA3.

\section{Determination of Swel stability}

Cells containing the GAL1-SWE1-myc12 construct were grown in YEPS (1\% yeast extract, $2 \%$ Bacto-peptone, $2 \%$ sucrose) at $23^{\circ} \mathrm{C}$ and shifted to $37^{\circ} \mathrm{C}$ for $2 \mathrm{hr}$. Galactose was then added to $2 \%$ and the cells were incubated for a further $10 \mathrm{~min}$ to induce Swel-myc12 expression. Cells were then harvested by centrifugation, resuspended at $10^{8}$ cells $/ \mathrm{ml}$ in labeling medium [yeast nitrogen base minus methionine, $2 \%$ sucrose, and $2 \%$ gal actose with $0.25 \mathrm{mCi} / \mathrm{ml}(0.183 \mathrm{~mm})$ Trans $^{35} \mathrm{~S}$-Label (ICN)], and incubated for a further $10 \mathrm{~min}$ at $37^{\circ} \mathrm{C}$. Labeled cells were collected by filtration, washed with prewarmed YEPD (1\% yeast extract, 2\% Bacto-peptone, 2\% dextrose), and resuspended at $3 \times 10^{7} \mathrm{cells} / \mathrm{ml}$ in fresh YEPD supplemented with $3 \mathrm{~mm}$ methionine and $0.5 \%$ casamino acids to prevent further labeling. Incubation was continued at $37^{\circ} \mathrm{C}$ for $4 \mathrm{hr}$. Aliquots of cells were diluted into ice-cold $10 \mathrm{mM} \mathrm{NaN}{ }_{3}$, harvested by centrifugation, washed with icecold $10 \mathrm{~mm} \mathrm{NaN}_{3}$, and frozen at $-80^{\circ} \mathrm{C}$. To determine Swel stability in synchronized cultures, cells were grown in YEPS at $23^{\circ} \mathrm{C}$, arrested by addition of $200 \mathrm{~mm}$ hydroxyurea for $3 \mathrm{hr}$ ( $>80 \%$ accumulation of large budded cells), and then shifted to $37^{\circ} \mathrm{C}$ for an additional hour to inactivate the temperature-sensitive alleles. Cells were processed as described above but in the presence of $200 \mathrm{~mm}$ hydroxyurea. Cell pellets were lysed in ice-cold $50 \mathrm{~mm}$ Tris (pH 7.5), $5 \mathrm{~mm}$ EDTA, $1 \mathrm{~mm}$ sodium pyrophosphate, $150 \mathrm{~mm}$ sodium chloride, 1\% NP-40, $1 \mathrm{~mm}$ sodium orthovanadate, $1 \mathrm{mM}$ PMSF, $1 \mu \mathrm{g} / \mathrm{ml}$ leupeptin, and $1 \mu \mathrm{g} / \mathrm{ml}$ pepstatin. Swel-myc12 was immunoprecipitated with the anti-c-M yc (9E10) antibody (Santa Cruz Biotechnology) from lysates containing equal amounts of radioactive label, and the immunoprecipitates were washed three times with lysis buffer, boiled 10 min in $1 \times$ SDS sample loading buffer, and separated by SDS-PAGE in $8 \%$ polyacrylamide gels. Dried gels were exposed to Molecular Dynamics storage phosphor screen for 24-48 hr, scanned on a Molecular Dynamics 445 SI Phosphorlmager, and analyzed with ImageQuant version 1.2 software.
Preparation of ubiquitination-competent yeast extracts

All extracts were prepared from cells del eted for the PEP4 gene. Cells were grown to an $O D_{600} \cong 1$, washed twice with ice cold water, and the cell pellet was resuspended in YEB [30 mM HEPES at $\mathrm{pH}$ 7.3, $100 \mathrm{~mm}$ sodium acetate, $1 \mathrm{~mm}$ EDTA, $1 \mathrm{~mm}$ EGTA , 10\% glycerol, 2 mM DTT, and proteinase inhibitor cocktail (Complete minus EDTA, Boehringer)]. Sodium acetate was added to a final concentration of $200 \mathrm{~mm}$ and cells were lysed with a French press. Extracts were centrifuged $10 \mathrm{~min}$ at $27000 \mathrm{~g}$ and $15 \mathrm{~min}$ at $136000 \mathrm{~g}$. After filtration through a $45-\mu \mathrm{m}$ filter, extracts were desalted on a G25 column $(8 \mathrm{ml})$ that was preequlibrated with YEB and concentrated with an amicon ultrafiltration cell (membrane YM 10). Alliquots of extracts (30-45 $\mu \mathrm{g} / \mu \mathrm{l}$ ) were flash frozen in liquid nitrogen and stored at $-70^{\circ} \mathrm{C}$.

\section{In vitro ubiquitination assay}

${ }^{35}$ S-Label ed Swel was produced by in vitro transcription/translation of a PCR fragment containing the SWE1 coding region and the T7 promoter (TNT T7 Quick Coupled Transcription/ Translation System, Promega). Mutant ubiquitin (R48) was expressed in E. coli and purified as described (Beers and Callis 1993).

U biquitination reactions (total volume $10 \mu \mathrm{l}$ ) contained $50 \mu \mathrm{g}$ extract or $75 \mu \mathrm{g}$ in case of the complementation experiment (50 $\mu \mathrm{g}$ cdc34-3 + $25 \mu \mathrm{g}$ met30-6), $5 \mu \mathrm{g}$ ubiquitin (Sigma), $1 \mu \mathrm{l} 10 \mathrm{x}$ ATP regenerating system (10 mM ATP, $600 \mathrm{~mm}$ creatine phosphate, $10 \mathrm{~mm}$ magnesium acetate, $1.5 \mathrm{mg} / \mathrm{ml}$ creatine kinase in YEB), $2 \mu \mathrm{l} 5 \times$ SCF-buffer ( $25 \mathrm{~mm}$ magnesium acetate, $5 \mathrm{~mm}$

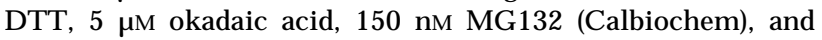
proteinase inhibitor cocktail (Complete minus EDTA, Boehringer) and $1.5 \mu \mathrm{l}$ of ${ }^{35} \mathrm{~S}$-label ed Swel. Reactions were incubated at $23^{\circ} \mathrm{C}$ for $5-15 \mathrm{~min}$ and terminated by addition of gel-loading buffer. Samples were separated on a 7.5\% SDS-polyacrylamide gel and analyzed by exposing the gel to a Phosphorlmaging screen.

\section{Acknowledgments}

We are grateful to $\mathrm{C}$. Wittenberg for pointing out the F-box in Met30, D. Finley and S. Sadis for the GST-MET30 and 6xHISubiquitin(R48) expression plasmids and hel pful discussions during the course of this work. We thank M. Snyder and P. Ross$M$ cdonald for the generous gift of the transposon mutagenized yeast library. We thank K. Flick, S. Haase, and C. Wittenberg for helpful suggestions on the manuscript and all members of the Scripps-cell cycle group in the McGowan, Reed, Russell, and Wittenberg laboratories for a stimulating environment and many constructive discussions. P.K. was supported by a Max Kade Fellowship. This work was supported by $\mathrm{N}$ ational Institutes of Health grant GM -38328 to S.I.R. and U.S. Public Health Service grant GM-53050 and by funds from the Searle Scholars Program/The Chicago Community Trust to D.J.L.

The publication costs of this article were defrayed in part by payment of page charges. This article must therefore be hereby marked "advertisement" in accordance with 18 USC section 1734 solely to indicate this fact.

\section{References}

Aligue, R., L. Wu, and P. Russell. 1997. Regulation of Schizosaccharomyces pombe Weel tyrosine kinase. J. Biol. Chem. 272: 13320-13325.

Amon, A., U. Surana, I. M uroff, and K. N asmyth. 1992. Regu- 
lation of $\mathrm{p} 34^{\mathrm{CDC} 28}$ tyrosine phosphorylation is not required for entry into mitosis in S. cerevisiae. Nature 355: 368-371.

Bai, C., P. Sen, K. H ofman, L. M a, M. Goebl, J.W. Harper, and S.J. Elledge. 1996. SKP1 connects cell cycle regulators to the ubiquitin proteolysis machinery through a novel motif, the F-box. Cell 86: 263-274.

Barral, Y., S. Jentsch, and C. Mann. 1995. G1 cyclin turnover and nutrient uptake are controlled by a common pathway in yeast. Genes \& Dev. 9: 399-409.

Beers, E.P. and J. Callis. 1993. Utility of polyhistidinetagged ubiquitin in the purification of ubiquitin-protein conjugates and as an affinity ligand for the purification of ubiquitinspecific hydrolases. J. Biol. Chem. 268: 21645-21649.

Booher, R.N., R.J. Deshaies, and M.W. Kirschner. 1993. Properties of Saccharomyces cerevisiae weel and its differential regulation of p34CDC28 in response to $\mathrm{G} 1$ and $\mathrm{G} 2$ cyclins. EMBO J. 2: 3417-3426.

Burns, N., B. Grimwald, P.B. Ross-M acdonald, E.Y. Choi, K. Finberg, S.G. Roeder, and M. Snyder. 1994. Large-scale analysis of gene expression, protein localization, and gene disruption in Saccharomyces cerevisiae. Genes \& Dev. 8: 1087-1105.

Chau, V., J.W. Tobias, A. Bachmair, D. Marriott, D.J. Ecker, D.K. Gonda, and A. Varshavsky. 1989. A multiubiquitin chain is confined to specific lysine in a targeted short-lived protein. Science 243: 1576-1583.

Deshaies, R.J., V. Chau, and M.W. Kirschner. 1995. Ubiquitination of the $G_{1}$ cyclin $C \ln 2 p$ by the $C$ dc $34 p$-dependent pathway. EMBO J. 14: 303-312.

Drury, L.S., G. Perkins, and J. Diffley. 1997. The Cdc4/34/53 pathway targets $\mathrm{Cdc} 6 \mathrm{p}$ for proteolysis in budding yeast. EMBO J. 16: 5966-5976.

Dunphy, W.G. 1994. The decision to enter mitosis. Trends Cell Biol. 4: 202-207.

Feldmann, R.M.R., C.C. Correll, K.B. Kaplan, and R.J. Deshaies. 1997. A complex of Cdc4p, Skplp, and Cdc53p/cullin catalyzes ubiquitination of the phosphorylated CDK inhibitor Siclp. Cell 91: 221-230.

Gietz, R.D. and A. Sugino. 1988. New yeast-Escherichia coli shuttle vectors constructed with in vitro mutagenized yeast genes lacking six-base pair restriction sites. Gene 74: $527-$ 534.

Guthrie, C. and G.R. Fink. 1991. Guide to yeast genetics and molecular biology, methods in enzymology, Vol. 194. Academic Press, San Diego, CA.

Henchoz, S., Y. Chi, B. Catarin, I. Herskowitz, R.J. Deshaies, and M. Peter. 1997. Phosphorylation- and ubiquitin-dependent degradation of the cyclin-dependent kinase inhibitor farlp in budding yeast. Genes \& Dev. 11: 3046-3060.

Hochstrasser, M. 1996. Ubiquitin-dependent protein degradation. Annu. Rev. Gen. 30: 405-439.

Huibregtse, J.M., M. Scheffner, S. Beaudenon, and P.M. Howley. 1995. A family of proteins structurally and functionally re lated to the E6-AP ubiquitin-protein Iigase. Proc. Natl. Acad. Sci. 92: 5249.

Irniger, S., S. Piatti, C. Michael is, and K. N asmyth. 1995. Genes involved in sister chromatid separation are needed for B-type cyclin proteolysis in budding yeast. Cell 81: 269-277.

Jiang, J. and G. Struhl. 1998. Regulation of the Hedgehog and Wingless signalling pathways by the F- box/WD40-repeat protein Slimb. Nature 391: 493-496.

King, R.W., J.M. Peters, S. Tugendreich, M. Rolfe, P. Hieter, and M.W. Kirschner. 1995. A 20s complex containing CDC27 and CDC16 catalyzes the mitosis-specific conjugation of ubiquitin to cyclin B. Cell 81: 279-288.

Lamb, J.R., W.A. Michaud, R.S. Sikorski, and P.A. Hieter. 1994.
Cdc16p, Cdc23p and Cdc27p form a complex essential for mitosis. EMBO J. 13: 4321-4328.

Lammer, D., N. M athias, J.M . Laplaza, W. Jiang, Y. Liu, J. Callis, M. Goebl, and M. Estelle. 1998. Modification of yeast Cdc53p by the ubiquitin-related protein Rublp affects function of the SCFCdc4 complex. Genes \& Dev. 12: 914-926.

Lanker, S., M.H. Valdivieso, and C. Wittenberg. 1996. Rapid degradation of the $\mathrm{G} 1$ cyclin $\mathrm{CIn} 2$ induced by CDK-dependent phosphorylation. Science 271: 1597-1601.

Lew, D.J. and S.I. Reed. 1993. Morphogenesis in the yeast cell cycle: Regulation by $\mathrm{Cdc} 28$ and cyclins. J. Cell. Biol. 120: 1305-1320.

-_-. 1995a. A cell cycle checkpoint monitors cell morphogenesis in budding yeast. J. Cell. Biol. 129: 739-749.

- - 1995b. Cell cycle control of morphogenesis in budding yeast. Curr. Opin. Genet. Dev. 5: 17-23.

Li, F.N . and M. Johnston. 1997. Grrl of Saccharomyces cerevisiae is connected to the ubiquitin proteolysis machinery through Skpl: Coupling glucose sensing to gene expression and the cell cycle. EMBO J. 16: 5629-5638.

Margottin, F., S.P. Bour, H. Durand, L. Selig, S. Benichou, V. Richard, D. Thomas, K. Strebel, and R. Benarous. 1998. A novel human WD protein, $h-\beta \operatorname{TrCP}$, that interacts with HIV-1 Vpu connects CD4 to the ER degradation pathway through an F-box motif. Mol. Cell 4: 565-574.

Marini, N.J., E. Meldrum, B. Buehrer, A.V. Hubberstey, D.E. Stone, A. Traynor-Kaplan, and S.I. Reed. 1996. A pathway in the yeast cell division cycle linking protein kinase C ( $\mathrm{PkCl}$ ) to activation of Cdc28 at START. EMBO J. 15: 3040-3052.

Mathias, N., S.L. Johnson, M. Winey, A.E.M. Adams, L. Goetsch, J.R. Pringle, B. Byers, and M.G. Goebl. 1996. Cdc53p acts in concert with Cdc4p and Cdc34p to control the G 1-to-S-phase transition and identifies a conserved family of proteins. Mol. Cell. Biol. 16: 6634-6643.

McKinney, J.D., F. Chang, N. Heintz, and F.R. Cross. 1993. $N$ egative regulation of FAR 1 at the start of the cell cycle. Genes \& Dev. 7: 833-843.

Muhlrad, D., R. Hunter, and R. Parker. 1992. A rapid method for localized mutagenesis of yeast genes. Yeast 8: 79-82.

Patton, E.E., A.R. Willems, D. Sa, L. Kuras, D. Thomas, K.L. Craig, and M. Tyers. 1998. Cdc53 is a scaffold protein for multiple Cdc34/Skp1/F-box protein complexes that regulate cell division and methionine biosynthesis in yeast. Genes \& Dev. 12: 692-705.

Piatti, S., T. Böhm, J.H. Cocker, J.F.X. Diffley, and K. N asmyth. 1996. Activation of S-phase-promoting CDKs in late Gl defines a "point of no return" after which Cdc6 synthesis cannot promote DNA replication in yeast. Genes \& Dev. 10: 1516-1531.

Reed, S.I., J.A. Hadwiger, and A.T. Lorincz. 1985. Protein kinase activity associated with the product of the yeast cell division cycle gene CDC28. Proc. Natl. Acad. Sci. 82: 4055-4059.

Rogers, S., R. Wells, and M. Rechsteiner. 1986. Amino acid sequences common to rapidly degraded proteins: The PEST hypothesis. Science 234: 364-368.

Ross, M.P., A. Sheehan, G.S. Roeder, and M. Snyder. 1997. A multipurpose transposon system for analyzing protein production, localization, and function in Saccharomyces cerevisiae. Proc. Natl. Acad. Sci. 94: 190-195.

Rudner, A.D. and A.W. Murray. 1996. The spindle assembly checkpoint. Curr. O pin. Cell. Biol. 8: 773-780.

Russell, P., S. Moreno, and S.I. Reed. 1989. Conservation of mitotic controls in fission and budding yeasts. Cell 57: 295303.

Schwob, E., T. Böhm, M.D. Mendenhall, and K. N asmyth. 1994. The B-type cyclin kinase inhibitor $\mathrm{p} 40^{\mathrm{SIC1}}$ controls the $\mathrm{G}_{1}$ to 
S transition in S. cerevisiae. Cell 79: 233-244.

Sia, R.A., H.A. Herald, and D.J. Lew. 1996. Cdc28 tyrosine phosphorylation and the morphogenesis checkpoint in budding yeast. Mol. Biol. Cell. 7: 1657-1666.

Skowyra, D., K.L. Craig, M. Tyers, S.J. Elledge, and J.W. Harper. 1997. F-box proteins are receptors that recruit phosphorylated substrates to the SCF ubiquitin-ligase complex. Cell 91: 209-219.

Sudakin, V., D. Ganoth, A. Dahan, H. Heller, J. Hershko, F.C. Luca, J.V. Ruderman, and A. Hershko. 1995. The cyclosome, a large complex containing cyclin-selective ubiquitin ligase activity, targets cyclins for destruction at the end of mitosis. Mol. Biol. Cell 6: 185-198.

Thomas, D., L. Kuras, R. Barbery, H. Cherest, P.L. Blaiseau, and Y. Surdin-Kerjan. 1995. Met30p, a yeast transcriptional inhibitor that responds to S-adenosylmethionine, is an essential protein with WD40 repeats. Mol. Cell. Biol. 15: 65266534.

Varshavsky, A. 1996. The $\mathrm{N}$-end rule: Function, mysteries, uses. Proc. Natl. Acad. Sci. 93: 12142-12149.

Verma, R., R.M . Fel dman, and R.J. Deshaies. 1997. SIC1 is ubiquitinated in vitro by a pathway that requires CDC4, CDC34, and cyclin/CDK activities. Mol. Biol. Cell. 8: 1427-1437.

Wach, A., A. Brachat, R. Pohlmann, and P. Philippsen. 1994. $\mathrm{N}$ ew heterologous modules for classical or PCR-based gene disruptions in Saccharomyces cerevisiae. Yeast 10: 1793-1808.

Willems, A.R., S. Lanker, E.E. Patton, K.L. Craig, T.F. N ason, N. M athias, R. Kobayashi, C. Wittenberg, and M. Tyers. 1996. Cdc53 targets phosphorylated $\mathrm{G} 1$ cyclins for degradation by the ubiquitin proteolytic pathway. Cell 86: 453-463.

Yaglom, J., M.H.K. Linskens, S. Sadis, D.M. Rubim, B. Futcher, and D. Finley. 1995. p34 ${ }^{\mathrm{Cdc} 28}$-mediated control of CIn3 cyclin degradation. Mol. Cell. Biol. 15: 731-741. 


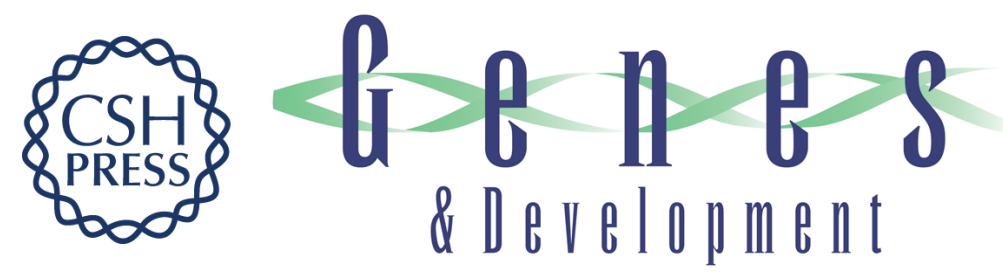

\section{Cdc34 and the F-box protein Met30 are required for degradation of the Cdk-inhibitory kinase Swe1}

Peter Kaiser, Rey A.L. Sia, Elaine G.S. Bardes, et al.

Genes Dev. 1998, 12:

Access the most recent version at doi:10.1101/gad.12.16.2587

References This article cites 47 articles, 25 of which can be accessed free at: http://genesdev.cshlp.org/content/12/16/2587.full.html\#ref-list-1

License

Email Alerting

Receive free email alerts when new articles cite this article - sign up in the box at the top Service right corner of the article or click here.

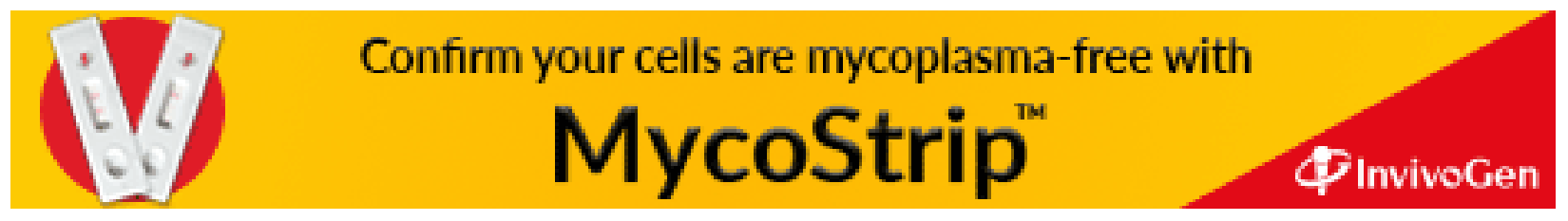

